\title{
Technological parameters for the production of cooked poultry and pork sausages enriched with non-traditional vegetable raw materials
}

\author{
Elvira Pyanikova ${ }^{1}$ and Mikhail Kolchanov ${ }^{2}$ \\ ${ }^{1}$ Southwest State University, 94, 50 Let Oktyabrya street, Kursk, 305040, Russia \\ ${ }^{2}$ Cashels Engineering Ltd, Aghamore, Cashels, Ballyhaunis, Co. Mayo, Ireland \\ E-mail:pyanikovaelvira@yandex.ru
}

\begin{abstract}
The results of the development of the technological scheme and parameters of the production of cooked sausage products from poultry and pork, enriched with protein-containing vegetable raw materials, are presented. It is proposed to introduce chickpea flour and lentil flour in a total amount of $5 \%$ in equal proportions of 1:1 into the sausage product recipe as a protein-containing vegetable additive. Previously, chickpea and lentil flour are mixed with aquafaba in different containers. Part of the water or ice introduced in the production of cooked sausages is replaced with aquafaba, obtained in the production of chickpea flour. Aquafaba is administered in an amount of 5\%. These mixtures are placed in the freezer 30 minutes before the start of cooking the minced meat and kept at a temperature of $-22^{\circ} \mathrm{C}$ for freezing. At the third stage of cutting, a frozen mixture of aquafaba, lentil and chickpea flour is added. The processing time is 3-5 minutes. This mixture in the technological process acts as a structure-forming component and improves the organoleptic properties of the finished product. The introduced additives allow you to get a functional product with an increased content of animal and vegetable protein, as well as increased vitamin and mineral value.
\end{abstract}

\section{Introduction}

The meat industry is one of the most important branches of the national economy. It provides the population with food products - meat, salted meat products, semi-finished products, ready-made quick-frozen dishes, sausage products and canned food.

Every year, the production of sausage products increases by $10-15 \%$. The share of cooked sausages in production is $60-70 \%$ [1].

Currently, there is a certain rise in the meat processing industry. Sausage production is developing in several directions:

- use of new raw materials and food additives;

- expanding the product range;

- mastering new equipment and technologies.

One of the important directions of the development of the meat sector in the food industry is the development and production of new types of products, for functional purposes.

Protein deficiency remains one of the world's major nutritional problems. In recent years, positive results have been achieved in the use of plant-protein sources in the fight against protein deficiency. One of the most important achievements is the possibility of replacing animal-protein products in the human diet with vegetable proteins [2].
Ready-made meat products are practically not considered as a source of vegetable proteins, vitamins and nutrients. The introduction of intensive technologies in animal husbandry has led to the fact that vitamin A has almost completely disappeared in the composition of meat, the content of thianine has decreased, vitamin $\mathrm{C}$ is absent, and vitamin $\mathrm{E}$ is practically not contained.

An effective way to solve this problem can be to develop a recipe for enriched cooked sausages. The consumption of such a sausage will eliminate the deficit in physiologically functional ingredients. As a result of combining the components of the recipe and the introduction of biologically active additives of plant origin, increase the biological properties.

Despite the high quality of proteins and other nutrients contained in meat offal, they are currently underutilized. New sources of protein need to be explored to ease the environmental pressures coming from the meat industry [3]. Pay attention to the possibility of using meat offal as meat substitutes for the production of a new range of sausage products with high nutritional value, improved technological and consumer properties. The effectiveness of the use of protein-containing raw materials of nonanimal origin, currently used as substitutes for meat proteins. 


\section{Materials and methods}

The composition of the cooked sausage product includes a minced meat system from poultry meat (chickens) GOST 31962-2013, pork meat GOST 31778-2012, chickpea and lentil flour TU 9293-009-89751414-10, aquafaba, table salt, sodium nitrate and ascorbic acid.

Chicken meat in comparison with the meat of other animals contains a large amount of protein and little fat. So, in comparison with beef, chicken meat contains 1.46 times less fat with almost the same protein content. In terms of protein content, chicken meat exceeds lean pork by 1.3 times, and fat pork by 1.76 times.

Pork improves the taste and increases the energy value of sausages. Pork has a delicate muscle tissue, high fat content and fusibility. But the more pork in the minced meat recipe, the lighter the color of the sausage [2].

The vegetable supplement consists of chickpea flour and lentil flour. Mixing these two cultures in equal proportions allows you to get a functional supplement balanced in terms of amino acid content. As a result, we can note the main positive effects when using a complex herbal supplement:

- simplification of the technology in comparison with the known methods of enrichment;

- improving the quality of raw materials;

- increase the content of vital elements in it.

Lentil flour is considered one of the best dietary products. Lentils contain carbohydrates, proteins, fats, including polyunsaturated, Omega-3, dietary fiber, which removes harmful substances from the body, reduces the risk of cardiovascular diseases, vitamin A, B vitamins, vitamin PP, minerals (phosphorus, manganese, potassium, iron, calcium, magnesium).

The introduction of lentil flour into the recipe of cooked sausages, the cost of which is significantly lower than the cost of meat, has a significant impact on reducing the cost of the final product. The amount of lentil flour was determined based on the organoleptic properties of the product and its ability to regulate the structural and mechanical properties of minced meat.

Chickpea flour can improve the indicators of vitamin composition: vitamin A, vitamin B1, vitamin B2, vitamin B6, vitamin PP. The composition of micro-and macronutrients is very rich. Chickpeas are rich in selenium. It is a powerful antioxidant that is difficult to find in food. A small portion will ensure a stable supply and eliminate the deficit of a valuable chemical element.

The addition of an enriching vegetable additive consisting of aquafaba, chickpea and lentil flour in a ratio of 1:1 to the recipe of a cooked sausage product as a structure-forming agent leads to an increase in its nutritional and biological value, a reduction in cost due to a reduction in the amount of raw meat and thereby expanding the range of cooked sausages.

Aquafaba is a viscous liquid obtained by boiling the fruits of legumes such as chickpeas, beans, and peas. Aquafaba has a number of advantages and benefits for the human body. It has an anti-inflammatory effect, normalizes the level of cholesterol and glucose in the blood, and activates the synthesis of certain hormones in the body. Aquafaba owes all these properties to the complex oligosaccharides and saponins that are part of legumes, including chickpeas and lentils.

The cost of aquafaba is approximately 1.5-2.3 times lower than the market price of egg whites on the Russian market, which reduces the cost of production, and, consequently, its cost. At the same time, the use of a plantbased component makes it possible to replace egg whites in the recipe of sausage products and increase the safety of the finished product, since egg white can serve as a possible source of salmonellosis.

Sodium nitrite is the sodium salt of nitric acid, used in the meat processing industry [5]. Sodium nitrite prolongs the shelf life of sausages, gives a pleasant and appetizing color to the product [6], does not allow the development of bacteria and infections in meat [7]. Along with the advantages, sodium nitrite is harmful to humans. With excessive consumption, it binds to the blood hemoglobin and blocks the exchange of oxygen in the body. Therefore, it became necessary to partially replace sodium nitrite with a safer ascorbic acid [8-11].

Poultry meat contains much less myoglobin pigment than beef and pork. Therefore, it is advisable to reduce the mass fraction of sodium nitrite in poultry sausages, which is usually calculated for the content of pigments in livestock meat.

When using myoglobin-poor raw materials, the introduced nitrite does not bind to the protein - pigment, but remains in the product in the form of residual nitrite, harmful to human health.

The conducted studies suggest that the reduction in the mass fraction of sodium nitrite in cooked poultry sausages from $6 \mathrm{mg} \%$ to $4 \mathrm{mg} \%$ does not cause significant changes in the color characteristics of the finished product. In addition, reducing the proportion of introduced nitrite can significantly reduce the concentration of residual sodium nitrite. This is directly related to the reduced content of muscle pigment-myoglobin [12].

The action of ascorbic acid is based on its strong reducing properties. It is used to accelerate the reactions of the formation of coloring of meat products, to prevent fat oxidation, as well as to improve the color and flavor characteristics of the finished product. This is not a harmful food supplement, because it is naturally present in many vegetables and fruits. In industry, it is made from glucose, by its synthesis.

The use of ascorbic acid contributes to the improvement of products with increased environmental safety.

\section{Equations and mathematics}

It is proposed to develop a recipe for a sausage product enriched with protein-containing vegetable raw materials. As a control sample, the recipe and production technology of cooked sausage "Doktorskaya" were selected. The proposed recipe for enriched boiled sausage is shown in Table 1.

The product yield of cooked sausages according to regulatory documents is $119 \%$. When calculating the yield of the finished product and losses per $100 \mathrm{~kg}$ of 
unsalted raw materials of water (ice) according to the production technology of boiled sausages, it is necessary to add $35-40 \mathrm{~kg}$. Unsalted raw materials include all ingredients except spices and aquafaba. Since aquafaba is introduced into the formulation in liquid form in an amount of $5.38 \mathrm{~kg}$, water (ice) will be introduced in an amount of $25.5 \mathrm{~kg}$.

Table 1. Recipe composition of cooked enriched sausage.

\begin{tabular}{|l|c|c|c|}
\hline \multicolumn{1}{|c|}{ Ingredients } & $\begin{array}{c}\text { Mass } \\
\text { fraction } \\
\text { \% per } \\
\text { output }\end{array}$ & $\begin{array}{c}\text { In kg per } \\
\text { 100 kg of } \\
\text { unsalted } \\
\text { raw } \\
\text { materials }\end{array}$ & $\begin{array}{c}\text { In grams } \\
\text { per } \\
\text { output }\end{array}$ \\
\hline Pork & 10 & 10.75 & 150 \\
\hline Poultry meat & 43 & 46.22 & 645 \\
\hline $\begin{array}{l}\text { Pork skins, } \\
\text { ground bones, } \\
\text { tendons, } \\
\text { cartilage, etc. }\end{array}$ & 25 & 26.88 & 375 \\
\hline Pork fat & 10 & 10.75 & 150 \\
\hline Aquafaba & 5 & 5.38 & 75 \\
\hline Chickpea flour & 2.5 & 2.7 & 37.5 \\
\hline Lentil flour & 2.5 & 2.7 & 37.5 \\
\hline Table salt & 1.86 & 1.847 & 27.7 \\
\hline Sodium nitrite & 0.07 & 0.07 & 1.05 \\
\hline Cardamom & 0.03 & 0.033 & 0.5 \\
\hline $\begin{array}{l}\text { Ascorbic acid } \\
\text { at the rate of } \\
0.5 \text { g per kg }\end{array}$ & 0.04 & 0.04 & 0.75 \\
\hline Total: & 100 & 107.37 & 1500 \\
\hline
\end{tabular}

Minced meat in the production of boiled sausage is formed from the following components:

$100 \mathrm{~kg}$ of unsalted raw materials $+7.37 \mathrm{~kg}$ of spices and aquafaba $+25.5 \mathrm{~kg}$ of water $=132.87 \mathrm{~kg}$.

After cooking boiled sausage at a given yield of 119 $\mathrm{kg}$, the production losses amounted to 132.87 $119=13.87 \mathrm{~kg}$.

Let's assume that these 13.87 are completely water, then, since $25.5 \mathrm{~kg}$ was added, and 13.87 evaporated, it turns out

$$
25.5-13.87=11.63 \mathrm{~kg} \text {. }
$$

That is, approximately $11.6 \mathrm{~kg}$ of water remained in the sausage without taking into account the native water, i.e., except for the water contained in the raw material itself. The losses also depend on the shell used, the technological process and the quality of the raw materials used.

In the production of model samples of boiled sausage, the minced meat mass was approximately $1.500 \mathrm{~kg}$ of unsalted raw materials with spices and akafaba. Ice was added to the recipe taking into account the fact that aquafaba has a liquid consistency in the amount of $120 \mathrm{~g}$. The minced meat mass was $1620 \mathrm{~g}$. In fact, three loaves weighing $475 \mathrm{~g}$ each were obtained. Accordingly, three loaves weighing $1425 \mathrm{~g}$. Production losses amounted to $195 \mathrm{~g}$ of which $120 \mathrm{~g}$, which is completely added water that has evaporated. The technical loss is $75 \mathrm{~g}$, which is about $5 \%$. The standards allow losses of up to $2.3 \%$. Thus, it was revealed that at least $165 \mathrm{~g}$ of ice or water should be added to the recipe to ensure the profitability of production.

The introduction of non-traditional vegetable proteincontaining raw materials (aquafaba, chickpea and lentil flour) into the recipe of cooked sausages affects the technological parameters of production.

\section{Equations and mathematics}

The technology of production of boiled sausage enriched with protein-containing vegetable raw materials is proposed. The proposed product has an improved component composition.

The technology of production of cooked sausages has its own characteristics due to the introduction of nontraditional raw materials. The quality is formed at each stage of the technological process, including the development of the recipe for the original minced meat. The technological process was worked out on control samples to obtain a minced meat mass of $1.500 \mathrm{~kg}$.

When accepting raw meat, check its compliance with the accompanying documents: the presence of stamps and their compliance with the actual category of meat; absence of defects (foreign smell, unusual for this type of raw material, poor exsanguination, bruising, etc.); thermal condition; terms and conditions of storage at the enterprise.

Preparation of raw meat (cutting, deboning, veneering). Fresh meat (pork and chicken fillet) is sent for maturation for 2-3 days at a temperature of $+4^{\circ} \mathrm{C}$. During maturation, the raw meat is cooled to a temperature of $+4^{\circ} \mathrm{C}$. For the preparation of $1.5 \mathrm{~kg}$ of minced meat, 150 grams of pork, 645 grams of chicken fillet, 375 grams of pork skins, 37.5 grams of chickpeas and lentils in a ratio of 1:1, 150 grams of pork fat, 75 grams of aquafaba, 27.5 grams of table salt and 0.75 grams of ascorbic acid, 0.5 grams of ground cardamom were prepared. Previously, these ingredients were kept in the refrigerator at a temperature of $+4^{\circ}$ for two days. In the control measurement, the temperature of the raw material immediately before preparation was $+4^{\circ} \mathrm{C}$.

Cutting. The pig half-carcass for boning is divided into parts: the shoulder blade, the thoracic part, including the neck and back. The spine sowbelly, located along the vertebral column, is separated along the line of the longest back muscles. The thickness of the ridge fat is not less than $1.5 \mathrm{~cm}$. From the prepared carcasses of the bird, the skin is separated, the carcass is rolled manually or with the help of devices for deboning the bird. The white and red meat obtained by manual deboning (muscle tissue from the thoracic and femoral parts of the carcasses, respectively) is used for the production of semi-finished products or sausages of the highest grades, and the remaining parts of the carcass (dorsal-scapular, wings) are sent for mechanical deboning.

Deboning. The separation of muscle, connective, and adipose tissue from the bones is performed manually with a knife. There should be no meat left on the bones. It is necessary to ensure that small bones do not get into the meat, which make it difficult to vein. Mechanical 
deboning of parts of poultry carcasses is carried out on screw-type presses.

Zhilovka. After deboning, pork meat is divided into lean, semi-fat, and fat pork. Boneless meat is veined, that is, fat, cartilage, tendons, connective films, large blood and lymphatic vessels, as well as blood clots and small bones are separated. Raw meat is cut into pieces of no more than $1 \mathrm{~kg}$.

Shredding and ambassador. Using a grate with holes with a diameter of $4 \mathrm{~mm}$, chopped pork, chicken fillet, pork fat for salting. After grinding, a salting mixture was added.

Ambassador. Per $100 \mathrm{~kg}$ of raw meat, salt and sodium nitrite are added according to the developed recipe. The temperature of the crushed raw materials should be plus $4-6^{\circ} \mathrm{C}$. At this temperature, the vital activity of microorganisms slows down, and the enzymes remain active. The minced meat is mixed with the salt mixture in stirrers for 3-4 minutes. Salted meat is aged in special containers in the premises at a temperature in the range from 0 to $+4^{\circ} \mathrm{C}$ for $6-24$ hours for maturation.

The salted meat was kept in the refrigerator at a temperature of $+4^{\circ} \mathrm{C}$ for 24 hours to mature.

We prepared additional ingredients in advance. This raw material is unpacked and the bulk raw material is sifted. Prepare a composition of spices and spices, as well as a mixture of chickpea and lentil flour mixed with aquafaba. Aquafaba is mixed with chickpea flour and lentil flour in equal proportions in different containers. 30 minutes before the start of the preparation of minced meat, these mixtures are placed in the freezer and kept at a temperature of $-22^{\circ} \mathrm{C}$ for freezing. Salted meat is also placed in the freezer.

Natural shells are soaked in cold water with a small addition of vinegar to eliminate foreign odors and give elasticity. After that, the shell is washed with warm water.

Preparation of minced sausage. The components are weighed according to the recipe. Preparation of minced meat begins with the processing of meat ingredients. At the first stage of cutting, the processing time of raw materials is 4-6 minutes. Poultry meat and non-fat pork are loaded into the cutter. Then add cold water or ice in portions. In the second stage, after careful grinding of non-greasy raw materials, spices and spices are added and fat pork (lard) is loaded. At the next stage of cutting, a mixture of aquafaba and lentil and chickpea flour is added. The processing time is 3-5 minutes. For 2-3 minutes before the end of the process of cutting or mixing, a solution of ascorbic acid is introduced. Pre-ascorbic acid is diluted in water. Ascorbic acid is used as an antioxidant to prevent the accumulation of nitrates, nitrites and $\mathrm{N}$ nitrozoamines in ground meat, to stabilize the color of ground sausage and accelerate coloring, acts as a preservative of animal fats, thereby affecting the shelf life of the finished sausage. The entire processing time is $8-12$ minutes. The temperature of the minced meat should not exceed $12^{\circ} \mathrm{C}$. With the help of a rotating disk and a transport cart, the cutter is unloaded. Then the minced meat is aged until it appears on the surface of a gray-green color.

Filling the minced meat shell and forming. The natural shell is washed with running water. A nozzle is prepared for filling the shell with minced meat. The filling of the shells is carried out on syringes with the use of vacuuming. The minced meat is fed into the shells evenly, avoiding voids. For syringing, it is necessary to use handguards with a diameter of at least half the diameter of the sausage shell. If air enters the loaf along with the minced meat, then it is removed by piercing the shell. After that, the loaves are tied with a nylon thread.

Sediment. It is produced for 2-3 hours at a temperature not exceeding $12^{\circ} \mathrm{C}$ before drying the shell.

Heat treatment is carried out at a temperature of 75 to $85^{\circ} \mathrm{C}$ and an air humidity of $50-80 \%$ to a temperature of $69-71^{\circ} \mathrm{C}$ in the center of the loaf and redness of the surface.

Cooling is carried out by showering with tap water with a temperature of no more than $15^{\circ} \mathrm{C}$ or in cooling chambers with a temperature of 0 to $8^{\circ} \mathrm{C}$ and a relative humidity of $95 \%$ until the temperature in the center of the loaf does not exceed $8^{\circ} \mathrm{C}$ for $3-15$ minutes. Then the sausage loaf is sent to the refrigerator at a temperature of $+4^{\circ} \mathrm{C}$ for 12 hours for further maturation.

Quality control for compliance with technological processes is carried out at all stages of sausage production. Before packaging, sausage products are also checked for compliance with regulatory documents.

Packaging and storage. Sausage products are packed in boxes made of corrugated cardboard and other types of containers that are allowed for food products, which ensure the safety and quality of products during transportation and storage. In each unit of transport packaging, sausage products of the same name, one production date, and one expiration date are packed. Store sausages at a temperature not exceeding $8^{\circ} \mathrm{C}$ and $75-80 \%$ relative humidity. The term of sale of boiled sausages of category $\mathrm{A}$ and $\mathrm{B}$ is not more than 14 days.

\section{Conclusion}

Having considered innovative methods of production of cooked sausages with additives from vegetable raw materials, we can draw the following conclusions:

- additives from vegetable raw materials containing vegetable protein in their composition, vitamin and mineral complex increase the nutritional and biological value of sausage products.

- introduction mixtures of aquafaba, chickpea and lentil flour are a structure-forming compound and give the product original organoleptic properties and improve structural and mechanical properties;

- significantly reduce the cost of the finished product by replacing expensive components with cheaper ones;

- the use of ascorbic acid contributes to the improvement of products with increased environmental safety.

\section{References}

1. N. L. Naumova, VestnikYUrGU 1 (2) 23 (2013)

2. R. Bressani, L. G. Elias, Advances in Food Research, 16100 (1968) 
3. C. Anzani, F.Boukid, L. Drummond, A. M. Mullen, C. Alvareza, Food Research International 137 109575 (2020)

4. M. S. Brewer, Meat Sci. 91 (4) 385 (2012)

5. F.K. Lücke, Fleischwirtschaft, 14391 (2008)

6. D. Majou, S. Christieans, Meat Sci. 145273 (2018)

7. R. Cammack, C.L. Joannou, X.Y. Cui, C. Torres Martinez, S.R. Maraj, M.N. Hughes, Biochim. Biophys. Acta 1411475 (1999)

8. J.J. Sindelar, A.L. Milkowski, AMSA White Paper 3 $10(2011)$

9. G.J. Sebranek, J.N. Bacus, Meat Sci., 77136 (2007)

10. X.F. Hospital, E. Hierro, M. Fernández, Int. J. Food Microbiol. 153395 (2012)

11. R.B. Pegg, F. Shahidi, Food \& Nutrition Press Inc., Trumbull, CT, 23 (2000)

12. A. M. Zolotareva, N. Bolortsetsed, All about meat 2 $23(2016)$ 